\title{
Contra o conexionismo abstrato: réplica a André Lemos
}

\section{Against the abstract connectionism: a reply to André Lemos}

\author{
FRA NCIS C O R Ü D I G E R * \\ Pontifícia Universidade Católica do Rio Grande do Sul, Programa de Pós-Graduação em Comunica- \\ ção Social. Porto Alegre-RS, Brasil \\ Universidade Federal do Rio Grande do Sul, Departamentos de Filosofia e Comunicação. Porto \\ Alegre-RS, Brasil
}

\section{RESUMO}

André Lemos atacou em número anterior desta revista as pretensões epistêmicas do pensamento crítico a respeito da técnica e da cibercultura, acusando-o de essencialista. O presente artigo contesta esse juízo, chamando atenção para três tipos de problemas. O primeiro é a carência de erudição e a falta de um entendimento mais profundo e esclarecido acerca do que é próprio da razão crítica. O segundo é a contradição performativa que o artigo incide ao jogar contra a crítica a linha de raciocínio à qual se opõe em vez da que preconiza. O terceiro é o endosso acrítico de uma corrente de ideias que, separando-se da prática de pesquisa que pode desenvolver, promove abstratamente um hiperempirismo de pouco alcance epistêmico.

Palavras-chave: André Lemos, razão crítica, teoria ator-rede

\begin{abstract}
André Lemos has published an article in this journal in which he attempts to invalidate the epistemic claims of critical thinking about technology and cyberculture, accusing it of essentialism. This article challenges this judgment, drawing attention to three types of issues. The first is a lack of academic references and, with this, of a deeper and well-informed understanding about what is proper to critical reason. The second is the author's performative contradiction of questioning the critique using the same line of thought that he opposes to instead of the one he advocates. The third is an uncritical endorsement of ideas that, separated from the research practice that can developed from them, promote a crude hyper-empiricism of little epistemic content.
\end{abstract}

Keywords: André Lemos, critical reason, actor-network theory

* Doutor em Ciências Sociais pela Universidade de São Paulo, leciona na Pontifícia Universidade Católica do Rio Grande do Sul. Também é professor nos Departamentos de Filosofia e de Comunicação da Universidade Federal do Rio Grande do Sul. E-mail: frudiger@ig.com.br 


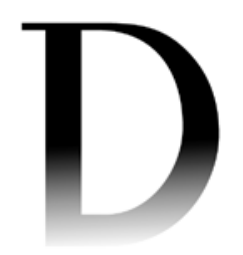

NDRÉ LEMOS, NO número anterior desta revista, investe contra a
crítica da técnica que ele chama de essencialista para apontar seus
abusos e, sobretudo, pouco alcance epistêmico, no momento em que com ela se aborda a cultura digital de que tanto tratam os trabalhos dele. Para o colega, encontramo-nos, no caso, diante de uma forma notoriamente equivocada de analisar o assunto, que por isso deve ser posta de lado em favor de outra, mais esclarecida e produtiva, como seria, segundo ele, a teoria ator-rede de Bruno Latour.

Pelo autor temos especial simpatia como pessoa e admiração como, talvez, o principal pesquisador dos fenômenos de mídia digital no Brasil. Será, porém, que sua análise, no artigo citado, dá conta do que se propõe? Julgamos que não, como será o caso de argumentarmos a partir de agora.

Lemos (2015) argumenta contra a abordagem teoricista e genérica da cibercultura, mas de fato seu artigo tem escopo mais específico, centrando fogo na crítica essencialista da técnica, senão na figura mesma da crítica, visto que, embora faça uso do termo no título do artigo e ligeiras referências ao discurso propagandístico a ela contraposto e para o qual ele mesmo contribuiu em sua colaboração com Pierre Lévy (Lemos; Lévy, 2012), é com a figura da crítica que o autor trava sua briga e institui sua causa no terreno dos estudos de mídia e cibercultura.

Autores como Morozov, Keen e Lanier entram no argumento apenas como exemplos setoriais contemporâneos de uma corrente de pensamento que faz escola há bem mais tempo, conforme ele deixa claro, recuando suas origens a Platão e Aristóteles, e que já influiu de modo marcante nos estudos de mídia via Escola de Frankfurt, igualmente mencionada por nosso colega em seu artigo "A crítica da crítica essencialista da cibercultura".

Apoiando-se em Latour, afirma ele que, como os entusiastas, os críticos da técnica e da cibercultura apagam ou saltam sobre a realidade das redes sociotécnicas e a variedade de seus atores para, dicotomicamente, tratar o assunto em um único bloco e postular abstratamente seu sentido em termos substancialistas (Lemos, 2015: 46). Para Latour, recordemos, a crítica nos põe no mau caminho ao nos afastar dos fatos em vez de nos fazer chegar mais perto deles; ela nos impede de dar nova vida a um empirismo com o qual poderíamos nos libertar da epistemologia moderna e suas dicotomias (Latour, 2004).

André Lemos endossa esse ponto de vista, mas vai vantajosamente além ao apontar alguns culpados por esse erro e comentar suas teses, conforme tudo isso se apresentaria nos campos de estudo da técnica e da cibercultura. No artigo citado, Latour apresenta seus argumentos contra a crítica, fazendo-lhe indicação na caricatura que acabou por lhe emprestar Jean Baudrillard. 
Reage hostilmente à ilusão do senso comum denunciada por Bourdieu, mas até onde sabemos não lhe analisa os escritos. Ridiculariza a tese do poder reciclador do capitalismo, mas não examina os argumentos e provas de Chiapello e Boltanski (Latour, 2004).

Lemos não se limita a acusar genericamente o "barbarismo crítico", como diz o outro, dos que se confrontam intelectualmente com a tecnologia, glosando ideias com maior variedade e detalhamento. A Heidegger, por exemplo, atribui-se a proeminência conferida à concepção essencialista da técnica e sua identificação como um modo de desvelamento do homem no mundo. A técnica seria a essência dos tempos modernos. A ciência, seu motor oculto. O processo todo ameaça a natureza e, assim, o nosso futuro, renovando a perspectiva de subjugação da primeira que teria começado com os gregos.

Em Jacques Ellul, o pecado seria a corroboração da tese heideggeriana, no sentido de que se afirma a criação, por parte da técnica, de um mundo em que, em vez do homem, é ela que tende a ocupar o posto dominante. Quer em um, quer no outro, Lemos comenta, o homem seria isolado e posto na situação de vítima. Denuncia-se erroneamente sua escravização e lançamento na decadência por uma tecnologia que se não nasceu, tornou-se infernal. Escrevendo em sua defesa, ambos apresentar-nos-iam o homem como um valor a ser preservado do perigo que representaria o avanço da técnica.

A Escola de Frankfurt também comparece no artigo, servindo para levar o argumento nele desenvolvido até o campo da comunicação. A exposição de suas ideias segue o convencionado: criou aquela escola teorias que têm como foco a capacidade de manipulação das massas pelos artefatos e sistemas mediáticos. $\mathrm{O}$ poderio dos mesmos teria, a seu ver, ensejado a formação de "uma sociedade na qual imperam a homogeneidade cultural, o achatamento dos valores pela mercantilização da cultura e a banalização das trocas comunicacionais" (Lemos, 2015: 36).

Apesar de eventualmente relevantes, diz-nos o autor, essas visões críticas são, em última instância, "crenças" que ignoram a "verdadeira realidade" (Ibid.: 44), "simplificações grosseiras", que fracassaram rotundamente, ao postular uma essência de sinal negativo para a tecnologia e sua influência na cultura (Ibid.: 37). Falharam elas todas em não ver que a técnica só existe em associação com outros fatores, é um vetor de transformações, em vez de uma entidade de significado único e linear, seja ele repressivo ou emancipatório. As teorias que conferem um sentido único e, portanto, substancial à técnica e à mídia se equivocam ao passarem por alto "os desvios e as reais associações que se colocam em prática nas mediações entre justamente as mídias, as tecnologias e a cultura" (loc. cit.). 
Os teóricos da cibercultura seguiriam pela mesma linha ao reduzir a pluralidade dos fenômenos e o movimento errático do rizoma em que a tecnologia acontece a um único fator e sentido. A variedade das redes sociotécnicas e os seus múltiplos planos de ação são algo que, em geral, lhes escapa à atenção, cegos que todos eles estão por um viés teórico que enferrujou (Lemos, 2015: 39). Os porta-vozes se renovam, mas em sua fala tudo estaria dado de antemão pelo cunho essencial dos artefatos: nenhuma de suas teorias desce aos fenômenos e suas articulações, devido à abordagem globalizante e unilateral.

Para nos tirar desse atoleiro, superar a postulação de substâncias, incluindo os jogos com suas oposições dicotômicas, todavia possuímos à mão a teoria ator-rede, em que o social, em vez da sua suposta essência, emerge da conexão entre vários tipos de entidades, do seu hibridismo. Com tanto, podemos pôr de lado a pura e simples decisão do sujeito tanto quanto as supostas lógicas que a transcendem, postuladas pela visão da matéria oriunda dos pensadores modernos. Em lugar disso, trata-se, desde o ponto de vista daquela primeira teoria, de seguir os rastros e observar as conexões entre os dados que se revelam à experiência. Só assim saberemos "o que realmente acontece nas associações entre humanos e não humanos" (Ibid.: 40) que, de fato, definiriam o campo da técnica e da cibercultura.

A vida social, em vez de uma totalidade estruturada em níveis com um dominante, é um processo de montagem e remontagem de situações em que intervêm atores humanos e não humanos; é uma rede de conexões heterogêneas, em que a técnica apresenta-se pontual e erraticamente, a cada vez de maneira diversa (Ibid.: 42). A visão crítica peca por escondê-lo ao purificar o processo com a instituição de discursos de sentido único a seu respeito, que a separam dos dados imediatos. O poder que a técnica assume, seja positivo ou negativo só tem lugar nesse discurso, porque, ainda que escondida, ela se encontra sempre mesclada, hibridizada com todo o resto, conectando pluralisticamente o social. O homo faber em nome do qual, para o bem ou mal, os essencialistas discursam e ao qual abstratamente ligam a técnica e seus poderes não é seu sujeito nem seu objeto, mas uma ilusão retórica que esconde o ziguezague formador do social (Ibid.: 42-43).

Aparentemente, tudo isso soa convincente, mas será mesmo? Segundo Lemos, o pecado da crítica, resumiremos, residiria em seu déficit empírico; estaria no fato de que, com ela, "perdemos a possibilidade de descrever as associações que formam empiricamente o social” (Ibid.: 30). Que isso seja o caso na maior parte das vezes, não questionamos. Ocorre que há de se perguntar se o que Lemos lhes impugna era o objetivo de seus porta-vozes e o que se pode e deve esperar da reflexão crítica enquanto tal, para não falar da pura e simples 
filosofia da técnica ou do ensaísmo ligeiro sobre a cibercultura. Que um ou outro dos pensadores citados em seu texto possam ter declarado o que o autor reclama é algo que se pode pesquisar documentalmente, caso a caso.

Adorno escreveu monografias em que, a despeito do mérito contido nos resultados, analisa em detalhe o programa de rádio da NBC (Adorno, 2008: 163-215) e a coluna de horóscopo do Los Angeles Times (Adorno, [1957] 2009), sem se limitar a ilustrar suas teorias. Em geral, afirmar-se-ia, contudo, que não é disso que se trata na maior parte dos críticos da tecnologia pela simples razão de, via de regra, seus sujeitos serem filósofos ou pensadores (cf. Cooper, 2002). Jacques Ellul, muito citado no texto, é um dos pensadores que mais exemplificou suas próprias teses - mas não há como tomar suas obras como monografias históricas ou relatos de pesquisa social sobre o assunto (cf. Ellul, [1954] 1968, 1962).

Queremos dizer com isso que há um abismo intransponível separando a atividade crítica dos vários setores da experiência, ou que um muro descomunal a protege de toda e qualquer objeção que possa provir de outro tipo de discurso com pretensão de saber? Decerto que não. Significa que o comentador em foco erra ao apresentar o que é próprio dessa atividade e, assim, não apenas se equivoca ao julgar o estatuto da crítica nos estudos de mídia e cibercultura, mas desenvolve um mau entendimento prático e teórico a respeito da própria tarefa em que está engajado no seu artigo e, talvez, nas suas pesquisas.

André Lemos talvez não tenha notado, mas lança mão, em seu artigo, de um entendimento muito pobre, senão equivocado, do que é a crítica em sua proposição histórica e filosófica mais ambiciosa e exigente, confundindo-a com oposição. Em seu artigo, o termo é posto no marco da filosofia dos valores e tratado como um tipo de partidarismo, considerando sua contraposição ao discurso dos tecnófilos. Aparentemente, verifica-se no texto um completo desconhecimento do que é mais próprio dessa tradição de pensamento, que começa com Kant, passa por Marx e chega até a Escola de Frankfurt e Foucault para ficar apenas nos seus grandes marcos reflexivos (cf. Foucault, 1997; Benhabib,1986; Honneth, 1991; Vandenberghe, 1997).

Que a atividade crítica várias vezes se autocompreenda mal e extrapole seus limites, assumindo um cunho total, essencialista, que lhe priva do próprio fundamento, não se discute, concordamos; mas isso se examina caso a caso, e não pondo no mesmo saco, sem uma análise documental detalhada e o devido embasamento na literatura especializada, um punhado muito diverso de pensadores e filósofos. Quem sabe a separação, para a técnica, de um espaço essencial e determinante, cujo sinal axiológico é negativo, se aplique a Ellul, 


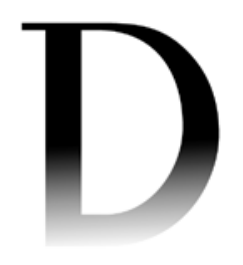

mas vale, digamos, para Adorno? Considerando as menções ao termo feitas em $O$ capital, valeria para Marx a denúncia de seu tratamento substancialista?

Deixando de proceder com esse cuidado, o opositor do essencialismo sucumbe em outro, em que toda a história da crítica é, por despacho sumário, monotonamente reduzida a um princípio único e substancial, a exemplo do que supostamente faria a crítica com conceitos como dominação ou indústria cultural. O pior, contudo, verifica-se no momento em que a crítica ao essencialismo metafísico da filosofia da técnica e das teorias da cibercultura, em vez de lhes aplicar os princípios de pesquisa que professa, contrapõe-lhes abstratamente uma metafísica do diverso e singular, ainda mais vazia e indeterminada.

Cego pela admiração, meu colega não percebe a armadilha em que Latour caiu em Reagregando o social ([2005] 2012) e, mais recentemente, em An inquiry into modes of existence ([2012] 2013), ao sistematizar em discurso um método justificado pelos resultados da pesquisa e análise de materiais, senão, caso do segundo texto, esboçar um sistema de conceitos que, estipulando os modos de existência e suas possibilidades de combinação, inevitavelmente conduz à ontologia - o contrário da crítica em Adorno, o edifício cuja destruição é tomada como tarefa por Heidegger.

Tratando-se do saber, convém que se distinga o trabalho de reflexão teórica feito em cima da experiência transmitida e elaborada do trabalho de pesquisa e análise com matéria nova e original, ainda que não se deva ignorar suas transições e dialética. As sínteses entre ambas só representam avanço quando se vai além da aplicação da primeira na segunda e se chega a resultados que importam em diferença no tocante ao conhecido.

Decerto que se pode confrontar teorias e pontos de vista, criticar-lhes abstratamente os limites e inconsistências, como estamos fazendo nesta réplica - mas isso é, no máximo, uma mediação reflexiva de uma atividade que, de ponto de vista da totalização do conhecimento, só se decide mesmo na prática de pesquisa que visa o novo e, por isso, se confronta com o desconhecido.

Disso Bruno Latour nos dá exemplo em pelo menos três obra importantes: A vida de laboratório; Aramis, ou o amor pela tecnologia; e Pasteur, guerra e paz com os micróbios (Latour; Woolgar, [1986] 1997; Latour, [1993] 1996, 2001); e não em seus tratados de metafísica, muito mal disfarçados de reflexão teórica e epistemológica (Latour, 2012, 2013). A razão está na presença, naqueles primeiros, de análises e resultados específicos que, por isso mesmo, podem ser confrontados e discutidos em referência a dados e documentação cujo acesso é público, a extensão pode ser checada e ninguém possui soberania - ao contrário dos outros textos citados. 
Ocorre, porém, que, contrariamente ao sugerido no artigo que estamos analisando, essa propriedade não é privilégio ou vantagem dos estudos que se valem da chamada Teoria Ator-Rede (TAR). Richard Barbrook (2009) e Thomas Streeter (2010), na área de estudos da cibercultura, assim como David Noble (1984) e David Gartman (1999), na de estudos sobre tecnologia, apenas para citar alguns exemplos, revelam que, apesar do estatuto filosófico, também a crítica é uma atitude capaz de intervir criativamente na pesquisa histórica e sociológica independentemente da avaliação que se possa fazer dos resultados.

Nosso colega passa isso por alto e, assim, transmite ao leitor um relato no mínimo enganoso do que está tratando ao sugerir que, enquanto o enfoque ator-rede seria, por si só, complexo, diferenciado e aberto, a crítica pecaria irremediavelmente por repetir um discurso linear, monótono e bitolado. Escapa-lhe que os conceitos de rede e actante não são formalmente mais densos e variados dos que os de sujeito e capital, embora estes ainda tenham um peso histórico e, talvez, ontológico muito maior sobre a episteme vigente.

Quer-se, no artigo, afirmar a superioridade de um empirismo sociológico sobre o criticismo artificiosamente reduzido à sua interface reflexiva. O principal argumento empregado contra o ponto de vista confrontado é, contudo, paradoxalmente abstrato e filosófico. Em vez de, em sendo possível, se submeter a crítica à análise em termos do esquema ator-rede, como seria coerente, adota-se o pior dos métodos daquela primeira para tentar invalidá-la.

O resultado é a contradição performativa, o ataque à crítica com o emprego dos procedimentos argumentativos que negativamente lhe caracterizariam. Diz-se que a crítica da cultura e a filosofia da técnica são essencialistas, não importa o viés. Os princípios analíticos do esquema ator-rede, no entanto, não intervêm na análise. O relato todo se caracteriza pela exposição filosófica mais tradicional, como fica cada vez mais claro, a cada passo dado na leitura do artigo.

Ao barbarismo de uma teoria crítica que supostamente morreu sem saber opõe-se uma retórica acusativa e programática, cujos problemas se refletem também na exposição das ideias que se encontra no artigo. Lemos, por exemplo, trata Heidegger como essencialista, estando nisso em companhia do neomarxista Feenberg (1999: 183-199). Um e outro, no entanto, passam por alto o fato de que, na obra daquele pensador, essência se entende como sentido, e sentido não é sinônimo de conteúdo, mas o ser mesmo dos múltiplos entes que ingressam no mundo. Para ele, lembremos, "filosofia e visão de mundo são absolutamente incomparáveis", já que a primeira entende "como fundação da verdade do ser a sua origem mesma; tem sempre de retomar-se naquilo 


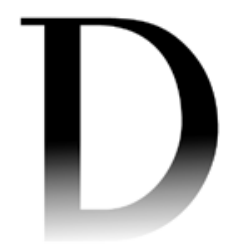

em que se funda e construir unicamente desde aí [isto é: o ser]" (Heidegger, [1936/1938] 2003: 48).

Em Heidegger, Ge-Stell não é um mero ente, mas o nome dado a uma interpelação da existência. Que ela provenha do ser é algo que discutimos em nosso livro sobre a matéria (Rüdiger, 2014). Para argumentar, não é, contudo, preciso ir tão longe. Basta lembrar que Heidegger fala a partir da história do ser, em vez de assumir o discurso de um ou outro ente, e por isso é estapafúrdio lhe acusar de essencialista, pelo menos do modo como faz nosso colega, isto é, como substância. Salvo é, claro, se há algo sem ser...

Quem sabe André Lemos tenha uma tese escondida, a de que Heidegger não é crítico da metafísica, a qual o filósofo tomou como causa destruir reflexivamente, mas um metafísico maior, que suplantou todos os demais. Seria encantador conhecê-la e discuti-la, mas até que ela se revele, convém conservar o que está consagrado. Heidegger sempre ressalvou que, em seus escritos, não estava falando da técnica, mas sobre a forma como a técnica veio a se tornar força formadora de mundo e objeto de discurso, inclusive nos escritos do autor que estamos comentando.

Sobre o espantalho do início dos anos 1980 que ele traz para o debate com o nome de Escola de Frankfurt, cremos ser desnecessário tecer quaisquer comentários. A falta de informação a respeito da literatura especializada sur-

1. Cf., apenas como exemplo, Cook, 1996; Paddison, 1996; Apostolidis, 2000; Witkin, 2003; Prokop, 2003; Rüdiger, 2004; Gunster, 2004; Jenemann, 2007; Hiver, 2010; Hullot-Kentor, 2010; Voirol, 2011; Quartana, 2011. gida desde então ${ }^{1}$ fala por si só sobre um tópico que nem precisaria constar no artigo para mantê-lo de pé, ainda que eivado de problemas.

Para Lemos, a alternativa ao entendimento essencialista da técnica, que a vê como fator isolado de cunho causal, é trabalhá-la como mediação, com o que qualquer pensador dialético consequente concordará, mas, no caso, é outro o sentido do termo. Desde a ótica latouriana que lhe subentende, mediação significa um "movimento de composição de humanos e não humanos, no qual sujeito e objeto se compõem mutuamente" (Lemos, 2015: 30). Quem não vê, contudo, que este, como outros que apontaremos, é um enunciado essencialmente abstrato e substancialista?

Diz-nos Latour (2012) que a TAR almeja pôr de lado os conceitos dramáticos e ideológicos para estudar o modo como os actantes humanos e não humanos são postos e refeitos localmente através da reconstrução de movimentos que os recortam e colam de um ponto para outro. A procura do sentido de tudo isso, seja pela abstração categorial, seja pela invocação de um ou mais sujeitos, nos levou para longe do seu conhecimento ao reduzir sua complexidade. Agora seria, portanto, o momento de explorar ou descrever em detalhe o modo como o mundo se faz e desfaz, tratar tudo o que puder como agência. 
Para nós, o resultado desse discurso é a criação de uma nova metafísica, em que tudo é tradução e é sempre irredutível; em que os entes meramente se conectam, para serem de novo projetados, como bem podemos apreciar na segunda parte, construtiva, do artigo de André Lemos. Deseja o autor escapar das visões generalizantes e redutoras por ele denunciadas na primeira, invocando um conexionismo entre atores humanos e não humanos que, à revelia das intenções, no entanto, reifica estas categorias ao trabalhá-las como dados, em vez de lhes seguir histórica e hermeneuticamente em seu ser conforme ele se revela através da linguagem.

Intoxicado por uma leitura subserviente dos escritos de Latour, o autor não percebe que sequer o que é ou não é humano é algo claro de antemão e, portanto, não pode ser relatado objetivamente como um dado entre as coisas, um ator entre outros, precisando ser seguido historicamente não apenas em sua conexão, mas, sobretudo, em seu ser, pois é função da história desse último, como ensina Heidegger.

Alberto Magno, convicto de ser sucessor de Adão, criado à imagem e semelhança de Deus, considerava os pigmeus, que não se julgavam humanos, uma espécie animal. Charles White, homem do Iluminismo, atribuía tanta diferença aos hotentotes que "os situava mais próximos dos macacos". No século XIX, os aborígenes australianos eram por muitos considerados macacos sem rabo, não sendo crime abatê-los. Para os nazistas, os judeus eram subumanos, visto que nem todos os que aparentavam ser humanos, para aqueles, o eram, embora suas vítimas estivessem certas de possuírem tal condição, ainda que atribuída por um deus todo-poderoso. Os aliados passaram a combater os nazistas sem dó nem clemência, acusando-os de serem desumanos, apesar de estes se considerarem cientificamente no topo ou, quiçá, além da humanidade (Übermensch) (cf. Fernandez-Armesto, 2007; Livingstone, 2011).

Pensa o autor que, pesquisando as conexões objetivas e pontuais que vão tecendo a rede do social, se pode "escapar de visões generalistas e ineficazes que tornam prescindíveis, por incrível que parece em se tratando de ciências humanas, os olhares para as relações, para os rastros das ações em análise" (Lemos, 2015: 44). Afinal, sempre que se parte da premissa de que tudo estaria dado nas essências, na substância, pouco restaria a descobrir no que de fato está acontecendo nas associações. Apenas revelando estas últimas é que se avançaria no conhecimento.

Que se responda à pergunta pela forma como o social se forma, reproduz e transforma, relatando como tudo o que podemos encontrar pela frente se relaciona com todo o resto; isto é, seguindo os rastros das conexões, à revelia do que pode significar para os participantes ou para a comunidade ideal a que 


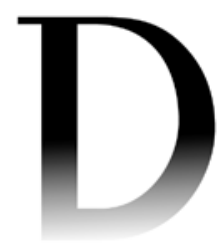

2. Confira distintos eixos aplicáveis ao assunto em questão neste artigo em, por exemplo, Steinert (2003) e Lovink (2012). Discussão mais ampla sobre a situação e perspectivas da crítica se encontra em Eagleton (1991), McCarthy e Hoy (1994),

Trivinho (2001) e Boltanski

(2009).

3. Latour relata que por dez vezes ao dia durante 20 anos foi obrigado, devido à falha no desenho de sua escrivaninha, a só poder abrir uma gaveta se as outras duas estivessem cuidadosa e completamente fechadas. O exemplo é uma tentativa de ilustrar a tese de que os objetos têm uma moral:

"Eu fui 'obrigado' a obedecer

à inoportuna lei moral, já que eu não estava 'autorizado' a deixar as três gavetas abertas ao mesmo tempo" (Latour, 2002: 255). À cadeira na qual se sentava enquanto o fazia, ele deveria pedir desculpas por lhe empurrar as costas, ou agradecer-lhe a oportunidade de descansar o corpo, se não as duas coisas ao mesmo tempo? Durante a infância, costumamos conferir intencionalidade humana ao que mais tarde, se nossa formação for secular e racional, revela-se de outro modo, menos antropomórfico. Que o ritmo da vida moderna

e a profusão de objetos que ela, sustentada na técnica e no capital, põe à nossa disposição nos levem, a despeito da publicidade, a perder de vista sua singularidade e diferenças, se aceita. Que engraçadinhos reivindiquem o poder de resgatá-las com a pregação baseada em exemplos retirados da conversa em mesa de bar é sinal da estupidez em que está hoje jogada parte expressiva das ciências humanas, conforme também se pode ver na resposta dada por alguns de seus porta-vozes à crítica, em geral arrasadora, que às suas mistificações dirigiram Alain Sokal e Jean Bricmond. se dirige o investigador - nos parece algo factível e que pode, para alguma audiência, ter seu interesse, apesar de não estar livre de questões.

No caso, ocorre, porém, a lembrança de que rastros e associações são, por princípio, abertos à descrição infinita, ainda que a cada momento possam ser determinados. Donde surge não apenas o problema de saber com que critério se pode avaliar sua propriedade e relevância das que são identificadas, mas principalmente porque se deveria preferir esse empirismo errante e ilimitado a uma hermenêutica capaz de fazer as experiências e materiais em análise dialogarem com um tema de reflexão mais amplo e significativo de acordo com o ponto de vista do investigador ${ }^{2}$.

Optando doutrinariamente pela primeira alternativa em vez de mostrar sua propriedade no campo de estudos da cibercultura com a indicação de estudos de caso bem informados por pesquisa empírica ou histórica ampla e detalhada, recomenda o autor linha de estudo que pode sucumbir no truísmo e, entre seus originadores, às vezes tangencia o elogio da idiotice sob o pretexto de introduzir o bom humor no argumento ${ }^{3}$.

Da irrelevância epistêmica que o esquema ator-rede pode se revestir, temos exemplo do autor no seu último livro, no capítulo em que se procede à análise do papel das redes sociais e dos aparatos de comunicação digital na chamada Primavera Árabe. Conclusão dela é a que, embora não seja uma revolta por elas provocada, também não é ela uma revolta em que esses actantes estavam ausentes: "É uma revolução na qual as mídias e redes sociais se constituíram como mediadores, tradutores, actantes, importantes para as associações que a realizou. Elas não estenderam, elas mediaram e traduziram" (Lemos, 2012: 172).

Cabe perguntar, porém, se não apenas elas, mas tudo que se possa enunciar para o caso: os automóveis, as roupas, os relógios, as garrafas d'água etc., também não se constituem da mesma forma, isto é: como actantes, tradutores e mediadores, em qualquer outro evento de sua época. Que, claro, não seja mesmo o modo em cada uma, significa que sempre importam e devam ser rastreadas, ou isto se decide em meio à reflexão aberta sobre sua influência no evento, a relevância que lhe emprestam os sujeitos e os objetivos e a problemática de estudo do investigador?

Pascal atribuía o fim da República Romana ao nariz de Cleópatra, que seduzira Marco Antônio, sem mexer com os sentidos de Otávio Augusto. Considerou-se um avanço no saber quando isso passou a ser explicado, por exemplo, pela incapacidade da aristocracia em transferir para si o apoio popular que, com a demagogia, conquistara o cesarismo. Sabe-se, para ir ao ponto, que a manipulação de um telegrama precipitou a Guerra Franco-Prussiana de 
1870. Qual é o peso e relevância que se deve dar a tanto quando se trata de analisar esse último acontecimento?

Wehler (1985) passa o fato por alto, situando a guerra, entre outros aspectos, em relação ao projeto de poder político e econômico nacional que articulou desigualmente os interesses dos junkers, industriais e trabalhadores fabris numa conjuntura internacional marcada pela competição imperialista. Latour e os seus analisarão o percurso que os telegramas seguiram, os métodos de transmissão dos papéis, a forma como se abreviava as palavras, os erros que o sistema comportava, os manuais de tradução do alemão para o francês usados pela agência Havas, a precisão com que o documento foi cortado pela tesoura de Bismarck, a forma com a informação chegou até as tropas e o povo etc.

Será que as ciências humanas desprezam os objetos passíveis de descrição objetiva em favor de abstrações substancialistas ou, em seus exemplares mais ilustrados, se moveram para problemáticas que, em seu momento e sob condições que não escolheram, revelaram-se mais significativas para seus sujeitos? Marx falou ampla e ostensivamente sobre o dinheiro, a moeda circulante, seus registros escriturais em bancos, repartições e empresas, salientando, porém, seu caráter de mediação objetiva e imediata do capital em sua análise conceitual das várias formas e contradições, movimentos e reações da economia moderna. Latour faria em relação a tanto a descrição dos processos de fabricação e design do papel moeda, das reconexões que implicam o recolhimento e distribuição das cédulas, da forma como as notas chegam ao bolso dos trabalhadores, dos lugares destinados a cada uma na gaveta da máquina registradora $\mathrm{e}$ como elas voltam ou não aos bancos4.

Sem que tanto tenha de importar em prejuízo, pode-se - logicamente optar por uma e outra forma de relato, conforme o que se deseja chamar atenção com a pesquisa empírica ou documental orientada racionalmente ${ }^{5}$. Desde esse ponto de vista, passível de ser cobrado dos seus praticantes, sempre que há responsabilidade, sua atividade se resume na manutenção da coerência do raciocínio e na administração de provas, como nos ensina Max Weber ([1922] 1973).

Ele também sabia, no entanto, do caráter demoníaco da existência, e é por causa dele que o racionalismo científico via de regra se encontra mesclado a várias outras influências. Em nosso contexto significa que, embora logicamente tenham o mesmo valor, as opções epistêmicas por nós feitas serão sempre motivo de disputa e sofrerão a interferência das circunstâncias em que estamos enfiados.

Questão que se decide pela correlação de forças dos intervenientes na discussão? Sim, mas apenas em parte. Sempre haverá quem, sem má consciên-
4. Ainda que se faça bem lembrar o óbvio à consciência reflexiva dos filósofos e cientistas sociais, isto é, que nossas atividades e relacionamentos são estruturados por condições materiais que nos escapam à escolha e se sustentam via a intermediação de todo o tipo de objetos, a começar pelo próprio corpo, cabe notar que sua análise de modo algum é algo novo, não sendo preciso ficar restrito à escola marxista para documentá-la. Nos estudos históricos está presente desde pelo menos Max Weber, conforme dá sinal sua História agrária romana (1891).

5. Langdon Winner esboça uma síntese entre o marxismo como teoria da luta de classes e o viés construtivista que ecoa nos primeiros escritos de Latour em Do artifacts have politics? (Winner, 1986). Os problemas que encontra no referido viés são examinados por ele em Social constructivism: opening the blackbox and finding it empty (Winner, 1993). Philip Brey avalia e rebate suas críticas e objeções desde o ponto de vista questionado em Social Constructivism for Philosophers of Technology ([1997] 2009). 


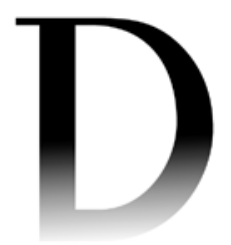

6. Exemplos disso não faltam no texto em análise, como dá prova este trecho: "O desengate é aquilo que faz fazer, o que mobiliza os planos de ações e causa as transformações no espaço, no tempo e nos tipos de atores (actantes mobilizando metamorfoses e reproduções)" (Lemos, 2015: 46). A palavra desengate pode ser substituída, sem perda de sentido para a frase, por uma vastíssima gama de substantivos, abstratos ou concretos; não faz diferença, basta o leitor fazer o teste. cia, a tempere e modifique com a força do argumento. Levando em conta esse princípio, resta o que dizer sobre o artigo em consideração.

A proposta apresentada nele é, em suma, a de relançar os estudos de mídia e cibercultura, valorizando a variedade da experiência e a riqueza de suas conexões, mas o que se entrega é um novo discurso do método totalmente abstrato e formal, que, salvo engano, se aplicaria a toda e qualquer situação ${ }^{6}$. As possibilidades de revelação que possuiria se dissolvem na exposição de um jogo de categorias metafísicas em que a experiência singular, necessariamente mediada pela tradição em vez da reflexão crítica bem determinada, dá lugar à fórmula metodológica.

Para nós isso significa o surgimento de uma nova metafísica, em que a transformação vale como sucedâneo da figura do devir, a trajetória significa sinônimo do sujeito e a rede vale como ente supremo. A metafísica das essências imutáveis, de cunho substancialista, é posta de lado por outra, de cunho formalista (metodológico), em que se afirma um mundo onde não há senão “ajustes, retificações, apropriações, desvios, dobras e acoplamentos" (Lemos, 2015: 45).

O pesquisador que emprega o esquema ator-rede almeja revelar-nos a riqueza e variedade dos seus temas de estudo, fugir do essencialismo que os simplifica e reduz a uma só significação. A falta de indicações bem determinadas empiricamente implica, no entanto, que, em vez de um repertório heurístico, no artigo se está de posse de uma nova forma de saber transcendental. Após servir à pesquisa especializada, os conceitos que nela se articularam, ou mesmo que dela surgiram, se coagulam em um sistema abstrato, dentro do qual toda situação pode, sem muito esforço, ser inserida.

$\mathrm{O}$ roteiro prescrito comporta todas as direções, o mapa que se desenha não prevê limites, visto que, no contexto, tudo pode ser conectado ao resto, não parece haver nada que não possa se transformar em outra coisa. "A tradução (outro nome da mediação) é um recurso metodológico interessante por implicar sempre na transformação dos atores em uma dada associação" (Lemos, 2015: 44, grifo meu).

Lemos deseja com seu texto nos ajudar a sair do círculo essencialista da crítica. À falta do criticismo, ele, no entanto, se entrega sem saber ao abraço da metafísica. Em seu artigo, o termo rede resume um complexo categorial que funciona como substituto do conceito de natureza dos antigos. Houve, talvez, uma ficção que nos convenceu a pensar que se poderia postular essências para o existente. Agora, surge outra, com intenção semelhante, inspirada no rizoma deleuziano e de acordo com a qual há que pensar uma "ontologia dos seres" (Ibid.: 41). 
Partindo dela, acompanhemos, pretende-se retirar da técnica a substancialidade que ela possuiria entre os defensores de uma visão essencialista que, vimos, atravessaria a história ocidental, mas jamais foi capaz de lhe dar conta positivamente. Para Lemos, chegou, em suma, a hora de "esvaziar os seres da técnica de sua realidade" (Lemos, 2015: 43). A alternativa proposta para tratar do tema, contudo, não nos parece melhor. Amparado nas doutrinas de seu guru (Latour, 2012), nosso colega se vale do repertório de modos de existência que aquele tirou não se sabe de onde para converter a técnica em uma categoria abstrata e transcendental, que se manifesta empiricamente em múltiplos seres.

Significa que a técnica se concretiza através de outros que não ela mesma, se não é um vetor de suas transformações.

A técnica não pode assim ser ainda designada por um objeto, uma coisa, um dispositivo. Antes, ela é uma trajetória do ser enquanto outro, ela é sempre transformação de um ser em outro. Todo objeto é apenas a marca temporária de uma trajetória (Lemos, 2015: 44, grifo no original).

Que transformações são em hipótese por ela determinadas, no entanto, não se fica sabendo, de modo que ela, a técnica, pode, em tese, ser arbitrária e abstratamente invocada em todas, até porque, fora o juízo ou argumento construído ad hoc pelo pesquisador, nada a determinada ou identifica como tal. Desejando sair-se do substancialismo em relação ao tema, cai-se na sua definição abstrata e vazia como modo de existência, que ninguém, salvo o arbítrio do criador da ideia, sabe de onde veio e o que lhe justifica - como ocorre em relação a outros tópicos do artigo em discussão.

A certa altura, por exemplo, afirma-se que a técnica "é o resultado de um movimento que vai retirar dos inertes e dos vivos um momento de metamorfose e reprodução e vai persistir na transformação" (Ibid.: 45). Que tipo de argumento, porém, é esse? Como se sabe de tudo isso? Existe aí algo mais que uma definição arbitrária? Que justificativa ele pode ter? Faz-se bem em defender o empirismo renovando o discurso especulativo e abstrato? Claramente a proposição nem se origina da pesquisa objetiva que o texto tanto preconiza, nem provém da elaboração de nenhuma pressuposição histórica objetivamente determinada.

Se tivesse lido Adorno em vez de repetir chavões e estereótipos a respeito de sua obra, refletido com o cânone da boa crítica em vez contrapor mecânica e abstratamente criticismo e dado empírico, Lemos perceberia que a crítica substancialista e simplificadora não é mero objeto de seu artigo, mas aspecto 


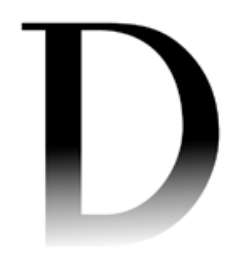

intrínseco à confecção do mesmo, já que, sem mediação, o autor contrapõe em bloco a TAR a todas as outras correntes de estudo da técnica e da cibercultura para, à primeira, apontar os acertos e, às segundas, reservar os erros.

Deseja o colega fazer a crítica ao essencialismo, mas à falta de dialética mediada pela autorreflexão, verifica-se em seu texto que o binarismo moderno por ele denunciado acaba se fazendo presente em seu próprio raciocínio. A crítica que ele empolga para contestar o substancialismo dos outros está cega à dependência de seu procedimento às dicotomias em que se baseia. A contestação do assunto não se vale do referencial que apregoa como sendo o mais vantajoso, mas, ao contrário, dos meios que aquela primeira, conforme a entende, parece ter lhe transmitido.

Destarte, acaba não sendo surpresa que, conforme vai passando da seção acusativa para a propositiva, o texto reintroduza no seio do enfoque que pretende defender o substancialismo que pretendia descartar. Apontamos, entre tantas, apenas duas provas disso. Afirma-se que "As redes sociotécnicas são formas de descrição da heterogeneidade dos dispositivos materiais de que dispomos em cada situação" (Lemos, 2015: 41). Noutro ponto, recorre-se às palavras de Latour: "As técnicas têm significados, mas elas os produzem por uma via especial de articulação que cruza as fronteiras do senso comum entre signos e coisas" (Ibid.: 44). Que estatuto tem estes proferimentos senão o essencialista?

Avançando, argumenta o autor contra o essencialismo dos críticos, acusando-os de promover uma "simplificação grosseira da realidade", sem notar que, assim, não apenas se arroga o privilégio de ter acesso a ela, mas assume o posto de demiurgo universal, que de antemão já sabe o que ela é ao defini-la como "um conjunto que se estabiliza a partir de mediação, tradução, rede, caixa-preta, delegação, inscrição, desvio" (Ibid.: 42). Dir-se-á que essa definição, como as mencionadas logo acima, é puramente metodológica; mas então a pergunta pelas condições de sua própria gênese é irrelevante, visto que tudo não passa de artifício arbitrário, enjambrado unicamente para fins de estudo pontual - e toda a causa genérica que se construa em cima do argumento será tida, por princípio, como insustentável.

Alguém julga ter achado a chave do real e agora pensa poder manejá-la de forma livre e soberana para nos dar o seu verdadeiro conhecimento. Tudo age visto ser, ao menos em potência, conectável. Nada mais escapa às redes sociotécnicas, visto que ninguém mais sabe o que não seria actante. Em vez de essências, afirma-se que só há híbridos (Ibid.: 41). Ocorre que se tudo é híbrido, híbrido é o nome do ser; as essências são ilusão; e assim estamos nós de volta à metafísica. De novo é tempo para, onde houver força, acionar a crítica. 


\section{REFERÊNCIAS}

ADORNO, T. Current of music. Londres: Blackwell, 2008.

. As estrelas descem à Terra. São Paulo: Unesp, 2009.

APOSTOLIDIS, P. Stations of the cross. Durham: Duke University Press, 2000.

BARBROOK, R. Futuros imaginados. São Paulo: Peirópolis, 2009.

BENHABIB, S. Critique, norm and utopia. Nova York: Columbia University Press, 1986.

BOLTANSKI, L. De la critique. Paris: Gallimard, 2009.

BREY, P. Philosophy of technology meets social constructivism. In: KAPLAN, D. (Org.). Readings in the philosophy of technology. Lanham: Rowman \& Littlefied, 2009. p. 98-111.

COOK, D. The culture industry revisited. Lanham: Rowman \& Littlefield, 1996.

COOPER, S. Technoculture and critical theory. Londres: Routledge, 2002.

EAGLETON, T. A função da crítica. São Paulo: Martins Fontes, 1991.

ELLUL, J. Propagandes. Paris: Armand Collin, 1962. . A técnica e o desafio do século. Rio de Janeiro: Paz e Terra, 1968.

FEENBERG, A. Questioning technology. Nova York: Routledge, 1999.

FERNANDEZ-ARMESTO, F. Então você pensa que é humano? São Paulo:

Companhia das Letras, 2007.

FOUCAULT, M. The politics of truth. Nova York: Semiotext(e), 1997.

GARTMAN, D. Auto opium. Nova York: Routledge, 1999.

GUNSTER, S. Capitalizing on culture. Toronto: Toronto University, 2004.

HEIDEGGER, M. Aportes a la filosofía. Buenos Aires: Biblos, 2003.

HIVER, M. Adorno et les industries culturelles. Paris: L'Harmattan, 2010.

HONNETH, A. The critique of power. Cambridge: MIT Press, 1991.

HULLOT-KENTOR, R. The exact sense in which the culture industry no longer exists. In: DURÃO, F. (Org.). Culture industry today. Cambridge: Cambridge Scholars, 2010.

JENEMANN, D. Adorno in America. Minneapolis: University of Minnesota Press, 2007.

KOSELLECK, R. Crítica e crise. Rio de Janeiro: Contraponto, 1999.

LATOUR, B. Aramis, or the love of technology. Cambridge: Harvard University Press, 1996.

. Pasteur, guerre et paix des microbes. Paris: La Découverte, 2001. . Morality and technology. Theory, Culture \& Society, Londres, v. 19, n.

5/6, p. 247-260, 2002. . Why has critique run out of steam? Critical Inquiry, Chicago, v. 30, n.

2, p. 225-248, 2004. . Reagregando o social. Salvador: Edufba, 2012. 
An inquiry into modes of existence. Cambridge: Harvard University Press, 2013

LATOUR, B.; WOOLGAR, S. A vida de laboratório. Rio de Janeiro: Relume, 1997.

LEMOS, A. A crítica da crítica essencialista da cibercultura. MATRIZes, São Paulo, v. 9, n. 1, p. 29-51, 2015. A comunicação das coisas. São Paulo: Annablume, 2012.

LEMOS, A.; LÉVY, P. Ciberdemocracia. São Paulo: Paulus, 2012.

LIVINGSTONE, D. Less than human. Nova York: St. Martin's Press, 2011.

LOVINK, G. Networks without a cause. Cambridge: Polity, 2012.

MCCARTHY, T.; HOY, D. Critical theory. Oxford: Blackwell, 1994.

NOBLE, D. Forces of production. New Brunswick: Transaction, 1984.

PADDISON, M. Adorno, modernism and mass culture. Londres: Kahn \& Averill, 1996.

PROKOP, D. Mit Adorno gegen Adorno. Hamburgo: VSA, 2003.

QUARTANA, P. Filosofia della musica rock. Gênova: Zona, 2011.

RÜDIGER, F. Theodor Adorno e a crítica à indústria cultural. 3. ed. Porto Alegre: Edipucrs, 2004.

. Martin Heidegger e a questão da técnica. 2. ed. Porto Alegre: Sulina, 2014.

STEINERT, H. Culture industry. Cambridge: Polity, 2003.

STREETER, T. The net effect. Nova York: New York University Press, 2010.

TRIVINHO, E. O mal-estar da teoria. Rio de Janeiro: Quartet, 2001.

VANDENBERGHE, F. Une histoire critique de la sociologie allemande. 2 vols. Paris: La Découverte, 1997.

VOIROL, O. Retour sur l'industrie culturelle. Réseaux, Paris, v. 2, n. 166, p. 125-155, 2011.

WEBER, M. Ensayos sobre metodologia sociologica. Buenos Aires: Amorrortu, 1973.

WEHLER, H. The German Empire, 1871-1918. Leamington Spa: Berg, 1985.

WINNER, L. The whale and the reactor. Chicago: The University of Chicago Press, 1986.

Social constructivism: opening the black box and finding it empty.

Science as Culture, Londres, v. 3, n. 16, p. 427-452, 1993.

WITKIN, R. Adorno on popular culture. Londres: Routledge, 2003.

Artigo recebido em 21 de julho de 2015 e aprovado em 10 de setembro de 2015 . 